\title{
Effects of Neonatal Stunting on the Development of Rats: Early and Late Effects of Neonatal Cortisone on Physical Growth and Skeletal Maturation
}

\author{
EDNA H. SOBEL ${ }^{(31)}$ \\ Department of Pediatrics and Rose F. Kennedy Center for Research in Mental Retardation and Human Development, \\ Albert Einstein College of Medicine, Bronx, New York, USA
}

\begin{abstract}
Summary
Cortisone acetate, $1.25 \mathrm{mg}$, was given im to each pup of eight eight-pup litters; saline was given to each pup of eight litters. At 21 days body weight, stem length, and length of long bones was less in the treated animals $(P<0.001)$. The number of ossification centers was greater in the treated animals $(P<0.05)$. Brain weight was less in the treated animals $(P<0.001)$. For 84-day-old animals body weight $(P<0.02)$ and length of most long bones $(P$ $<0.05)$ were less in the treated females. Body weight $(P<0.01)$, stem length $(P<0.01)$ and some bones $(P<0.02)$ were smaller in the treated males. There was no difference in the number of epiphyseal fusions. The brains of the treated males weighed less than those of the controls $(P<0.01)$.

The effect on linear growth is in conformity with observations in children but the accelerated skeletal maturation was unexpected. The effect on skeletal maturation was less persistent than that on bone length.
\end{abstract}

\section{Speculation}

The unexpected acceleration of skeletal maturation found at weaning in rats given corticosteroid treatment in the neonatal period offers at least a partial explanation of persistent stunting because the expected depression of physical growth was found.

The experiments to be reported were conducted as part of a research program designed to examine the long term effects of neonatal stunting on the later physical growth and behavioral development of rats. Growth retardation as a result of adverse conditions during fetal or neonatal life may have permanent effects on weight $(15,27)$, length $(8,25)$, and on the growth of several organs, including the brain $(9,15)$.

Cortisone given during the neonatal period has been shown to affect certain aspects of growth in the rat. Winick and Coscia (28) reported that rats given $1 \mathrm{mg}$ cortisone acetate were stunted in body weight and in the weight or composition of several soft tissues. Sawano et al. (23) noted growth retardation by 1 week of age (body weight) in rats given $1 \mathrm{mg}$ cortisol or of cortisone acetate on the first postnatal day, as did Schapiro (24). Cotterrell et al. (4) reported no effect on body weight, although brain weight was reduced; they used ip cortisol acetate, which is not absorbed well. Ioachim (14) used various doses of cortisone in rats from 1-4 days of age; even those animals given $1.25 \mathrm{mg}$ cortisone acetate on day 4 gained very poorly until age 31 days, and a deficit in body weight and cellular growth was still present at 120 days. Howard induced growth retardation in mice by implanting pellets of corticosterone on the second day of life. She reports reduced weight gain (12) and changes in chemical composition of the brain (11) comparable to those induced by food restriction.
This study was undertaken to assess the early and long range effects of neonatal cortisone treatment on the growth and skeletal maturation of rats.

\section{MATERIALS AND METHODS}

All rats used were offspring of Cesarian-derived Sprague-Dawley descendents purchased from the Charles River Laboratories as young adults of proven fertility. The animals were maintained in air-conditioned rooms with reversed light-dark cycle (7 PM-7 AM) so that they could be worked with during their waking hours. Males were housed singly and females in groups of three or four during at least 2 weeks of acclimitization before mating. Pregnant females were housed in individual polycarbonate cages. Before breeding and during pregnancy pelleted Teklad rat and mouse diet ( $4 \%$ fat, $24 \%$ protein; source: Teklad, Winfield, IA) and water were provided; nursing females were provided with Purina mouse chow pellets (11\% fat, $17 \%$ protein). To combat infection tetracycline hydrochloride $(400 \mathrm{mg} / \mathrm{liter})$ was added throughout the first week of nursing; fresh solution was prepared each day. Water and Teklad mouse and rat diet were provided for weanlings, which were housed in like-sex groups of three or four.

Pups were redistributed among the animals giving birth within $24 \mathrm{hr}$ to construct litters of eight pups each. A total of 16 eightpup litters resulting from four separate breedings was used. An extra litter of eight pups was kept to provide replacements for animals dying in the first week; data from replacement pups was not used in analyses of results.

Cortisone acetate, $1.25 \mathrm{mg}$ in $0.05 \mathrm{ml}$ solution (Upjohn, sterile aqueous suspension) was given im on day 4 to each pup of eight litters; $0.05 \mathrm{ml}$ isotonic saline was given in the same site to each pup of eight litters. Cortisone acetate was chosen because it is much more available than is corticosterone. Its prolonged effect when given im permits the administration of only one injection. The dose of $1.25 \mathrm{mg} /$ animal given on day 4 was chosen because of Ioachim's experience that this amount, although toxic in some respects, permits survival of most of the animals; given earlier than day 4 runting syndrome may lead to the death of most of the pups (14).

\section{GROWTH STUDIES}

Fifty pups from four treated and four control litters were reared to age 21 days, and 52 pups from eight litters were reared to age 84 days; during this period they were weighed weekly. Animals were killed at 21 or 84 days by ip injection of pentobarbital. Body weight was determined with a Mettler top-weighing balance. Stem length was determined after death with a modification of the measuring board described by Acheson (1), which allows accurate measurement from tip of nose to base of tail. Brain weight at 21 days was determined on 44 of the animals; the brains of the males 
in one of the experiments were weighed at age 84 days. The carcasses were skinned and eviscerated.

The bodies of 21-day-old animals were prepared by chemical treatment after removal of skin and viscera but without separation of limbs or removal of soft tissues. At age 84 days, limbs were removed and cleaned of soft tissues by placement with a colony of Domesties escarbochos (Courtesy New York Museum of Natural History). Skeletons were cleared with $\mathrm{KOH}$ and increasing concentrations of glycerin, stained with Alizarin red-S, and stored in glycerin (method of Dawson 5). Bone length was measured with calipers, using a stereoscopic microscope. Skeletal maturation was assessed from the total number of ossification centers present at age 21 days and from the number of epiphyseal fusions found in selected bones at 84 days (Joss et al. (16)). The paired (Student) or unpaired (Fisher) t-test, as suitable, was applied to the physical measurements obtained.

\section{RESULTS}

More nurslings died in the treated than in the control litters. The cortisone-treated pups furred late and in an abnormal pattern, with bare patches on the head and over the back. This pattern was described by Ioachim (14). Fur elsewhere was scanty and there was usually a conspicuous bald area over the left hip where the cortisone had been injected. The fur looked normal by about 35 days of age.

\section{FINDINGS AT 21 DAYS}

The results for males and females were pooled, (Table 1) because no difference was found by t-test between any of the measurements for control animals at this age. Twenty-five treated animals (10 female, 15 male) were compared to 25 controls (13 female, 12 male). Body weight, stem length, length of tibia, femur, and humerus were all less in the treated animals $(P<0.001$, Table 1). The number of ossification centers, however, was greater in the treated animals $(P<0.05)$. Brain weight was less in the treated animals $(P<0.001)$.

\section{FINDINGS AT 84 DAYS}

The results for 84-day-old animals were analyzed separately for males and females because of the larger body size of males and the relatively advanced skeletal maturation of females (Joss $e t$ al. (16), Hughes and Tanner (13)). For females, there were 13 control and 12 treated; for males 15 control and 12 treated.

Females (Table 2). Body weight and the length of most long bones were less in the treated females. There were no differences between treated and control in length of metacarpal III or metatarsal III, and no difference in the number of epiphyseal fusions.

Males (Table 3). Body weight, stem length and long bones were smaller in the treated males. In the males, metacarpal III and metatarsal III were shorter in the treated; the number of epiphyseal fusions was not different in treated and control. The brains of the treated males weighed less than those of the controls $(P<0.01)$.

\section{DISCUSSION}

The results at age 21 days indicate that, for the rat, stunting in adult life as a consequence of neonatal cortisone treatment can be explained by retarded growth of long bones combined with accelerated skeletal maturation. The effect on linear growth is in conformity with observations in children $(2,10)$, but the accelerated skeletal maturation was entirely unexpected. No analysis of skeletal maturation of children treated with corticosteroids in the neonatal period has been published.

The reason for persistent retardation of linear growth is not established, but could lie in permanent impairment of growth hormone release or of thyroid function (23). Mosier (21) proposed that incomplete compensatory growth in rats given cortisone as weanlings might be attributable to alterations in chondrocytes. Laron et al. (20) described morphologic changes in the epiphyseal
Table 1. Results in 21-day-old animals (mean $\pm I S D$ )

\begin{tabular}{lccc}
\hline & Treated & Control & $P$ \\
\hline Number & 25 & 25 & \\
Body wt, g & $50.44(9.04)$ & $62.96(5.06)$ & $<0.001$ \\
Stem length, mm & $112.96(7.18)$ & $125.32(3.89)$ & $<0.001$ \\
Femur, mm & $14.76(1.44)$ & $17.28(1.26)$ & $<0.001$ \\
Tibia, mm & $17.15(1.60)$ & $20.37(1.29)$ & $<0.001$ \\
Humerus, mm & $14.41(1.44)$ & $16.88(1.20)$ & $<0.001$ \\
No. of ossification cen. & $118.44(16.29)$ & $107.56(12.58)$ & $<0.05$
\end{tabular}

ters

\begin{tabular}{llll} 
Brain wt, g & $1.44(0.09)^{1}$ & $1.55(0.07)^{1}$ & $<0.001$ \\
\hline
\end{tabular}

${ }^{\prime} n=22$.

Table 2. Results in 84-day-old females (mean $\pm 1 S D$ )

\begin{tabular}{lccc}
\hline & Treated & Control & $P$ \\
\hline Number & 12 & 13 & \\
Body wt, g & $244.25(23.47)$ & $268.08(22.76)$ & $<0.02$ \\
Stem length, mm & $209.92(4.14)$ & $213.46(8.17)$ & NS \\
Femur, mm & $30.07(1.13)$ & $31.03(1.18)$ & $<0.05$ \\
Tibia, mm & $35.26(1.48)$ & $36.61(1.29)$ & $<0.05$ \\
Humerus, mm & $25.00(0.71)$ & $26.08(0.86)$ & $<0.01$ \\
Metacarpal III, mm & $7.10(0.65)$ & $7.37(0.64)$ & NS \\
Metatarsal III, mm & $15.00(0.75)$ & $15.48(0.75)$ & NS \\
No. of epiphyseal fu- & $40.79(1.70)$ & $41.58(0.70)$ & NS \\
\multicolumn{1}{l}{ sions } & & & \\
\hline
\end{tabular}

Table 3. Results in 84-day-old males (mean $\pm S D$ )

\begin{tabular}{lccc}
\hline & Treated & Control & $P$ \\
\hline Number & 12 & 15 & \\
Body wt, g & $397.75(40.00)$ & $452.20(38.82)$ & $<0.01$ \\
Stem length, mm & $236.58(7.88)$ & $241.80(4.87)$ & NS \\
Femur, mm & $33.02(0.91)$ & $33.63(0.88)$ & $<0.10$ \\
Tibia, mm & $39.37(1.40)$ & $40.41(1.23)$ & NS \\
Humerus, mm & $27.51(0.73)$ & $28.26(0.76)$ & $<0.02$ \\
Metacarpal III, mm & $7.40(0.43)$ & $8.01(0.61)$ & $<0.01$ \\
Metatarsal III, mm & $15.99(1.07)$ & $16.63(0.49)$ & NS \\
No. of epiphyseal fu- & $40.35(1.22)$ & $40.50(1.56)$ & NS \\
$\quad$ sions & & & \\
Brain wt, g & $1.78(0.13)^{1}$ & $1.99(0.14)^{2}$ & $<0.01$ \\
\hline ' $n=7$. & & & \\
${ }^{2} n=9$. & & & \\
& & &
\end{tabular}

cartilage of rats given large dose corticosteroids (6-methylprednisolone, $1 \mathrm{mg}$ to males weighing about $100 \mathrm{~g}$ ). The changes reflected growth inhibition but were not suggestive of potential acceleration of skeletal maturation. Peck et al. (22) documented inhibited protein and RNA synthesis in cultured isolated bone cells. Kunin and Meyer (19) analyzed the intermediary metabolism of epiphyseal cartilage from cortisone-treated rats. Glucose utilization was increased and their results indicated that it might be going to glycogen rather than via glycolytic pathways. Deardon and Mosier (7) observed marked and persistent increase in glycogen content of tibial chondrocytes in rats that had been given sc injections of cortisone acetate ( $5 \mathrm{mg}$ daily for 5 days); their animals were 42 days old at the beginning of the study. Decreased cell size persisted longer than inhibition of weight gain and tail growth and may offer an explanation for accelerated ossification of cartilage in our animals, which were treated at a much younger age. Deardon and Espinosa (6) found substantially more hydroxyapatite crystals in cortisone-treated than in fasted rats, in which there was little or none. Increased calcification is one of the manifestations of aging in cartilage of both rats and human beings (3).

In our study the effect on skeletal maturation was less persistent than that on bone length; the difference in skeletal maturation was no longer evident at age 84 days. However, in many of the animals, both treated and control, all the epiphyses in the bones selected 
for the method (16) had fused. Differences might have been seen if the experiment had been terminated when the animals were younger.

The metacarpal and metatarsal bones have different growth characteristics from the long bones because they have only one epiphysis and cease growing at about 70 and 80 days of age (discussed in Joss et al. (17)). Therefore, the adequate size of these bones in the treated females is taken as suggesting that the effect of the treatment on skeletal maturation was of less duration than that on linear growth. However, these bones of the paws were short in the treated males. This observation is interpreted as supporting the findings of others that all effects of stunting agents are more persistent in male than in female rats (18). Accelerated skeletal maturation at an early age would be expected to have an adverse effect on growth, because it necessarily imposes a limit on mature size unless the rate of linear growth is accelerated equivalently (26).

The decreased brain weight at 21 days, and its persistence in those animals (males) in which the brain was weighed at 84 days might have implications for behavioral competence. The growth studies were terminated at age 84 days because linear growth is very slow and little further advance in epiphyseal fusion can be expected. Therefore, the possibility of continued compensatory growth of the brain cannot be answered from this study.

\section{CONCLUSION}

Rats given $1.25 \mathrm{mg}$ cortisone acetate im at age 4 days were stunted in length and weight but had accelerated skeletal maturation at age 21 days. The stunting persisted, especially in males, to age 84 days although skeletal maturation was not different from that of the controls at that age. Brain weight was less at 21 days in treated animals and at 84 days in treated males; no data are available for treated females at that age.

\section{REFERENCES AND NOTES}

1. Acheson, R. M., MacIntyre, M. N., and Oldham, E.: Techniques in longitudinal studies of the skeletal development of the rat. Brit. J. Nutr., 13: 283 (1959).

2. Blodgett, F. M., Burgin, L., Iezzoni, D., Gribetz, D., and Talbot, N. B.: Effects of prolonged cortisone therapy on the statural growth, skeletal maturation and metabolic status of children. N. Engl. J. Med., 254: 636 (1956).

3. Bonucci, E., and Deardon, L. C.: Matrix vesicles in aging cartilage. Fed. Proc., 35: 163 (1976).

4. Cotterrell, M., Balazs, R., and Johnson, A. L.: Effects of corticosteroids on the biochemical maturation of rat brain: Postnatal cell formation. J. Neurochem., 19: 2151 (1972)

5. Dawson, A. B.: A note on the staining of the skeleton of cleared specimens with Alizarin Red S. Stain Technol., I: 123 (1926).

6. Deardon, L. C., and Espinosa, T.: Comparison of mineralization of the tibial epiphyseal plate in immature rats following treatment with cortisone, propylthiouracil or after fasting. Calcified Tissue Res., 15: 93 (1974).

7. Deardon, L. C., and Mosier, H. D.: Long-term recovery of chondrocytes in the tibial epiphyseal plate in rats after cortisone treatment. Clin. Orthop., 87: 322 (1972).

8. Dickerson, J. W. T., and Hughes, P. C. R.: Growth of the rat skeleton after severe nutritional intrauterine and postnatal retardation. Resuscitation, $1: 163$ (1972). 9. Dobbing, J., and Widdowson, E. M.: The effect of undernutrition and subsequent rehabilitation on myelination of rat brain as measured by its composition. Brain, 88: 357 (1965).

10. Falliers, C. J., Tan, L. S., Szentivanyi, J., Jorgensen, J. R., and Bukantz, S. C.: Childhood asthma and steroid therapy as influences on growth. Amer. J. Dis. Child., 105: 127 (1963).

11. Howard, E.: Effects of corticosterone and food restriction on growth and on DNA, RNA and cholesterol contents of the brain and liver in infant mice. J. Neurochem., 12: 181 (1965).

12. Howard, E., and Granoff. D. M.: The effect of neonatal food restriction in mice on brain growth, DNA and cholesterol, and on adult delayed response learning. J. Nutri., 95: 111 (1968).

13. Hughes, P. C. R., and Tanner, J. M.: The assessment of skeletal maturity in the growing rat. J. Anat., 106: 371 (1970).

14. Ioachim, H. L.: The cortisone-induced wasting disease of newborn rats: histopathological and autoradiographic studies. J. Pathol., 104: 201 (1971).

15. Jackson, C. M., and Stewart. C. A. The effects of inanition in the young upon the ultimate size of the body and of the various organs in the albino rat. J. Exp. Zool., 30: 97 (1920).

16. Joss, E. E., Sobel, E. H., and Zuppinger, K. A.: Skeletal maturation in rats with special reference to order and time of epiphyseal closure. Endocrinology, 72: 117 (1963).

17. Joss, E. E., Zuppinger, K. A., and Sobel, E. H.: Effect of testosterone propionate and methyl testosterone on growth and skeletal maturation in rats. Endocrinology, 72: 123 (1963).

18. Kennedy, G. C.: The development with age of hypothalamic restraint upon the appetite of the rat. J. Endocrinol., 16: 9 (1957).

19. Kunin, A. S., and Meyer, W. L.: The effect of cortisone on the intermediary metabolism of epiphyseal cartilage from rats. Arch. Biochem., 129: 421 (1969).

20. Laron, Z., Arie, B-Z., and Kende, S.: Effectiveness of growth hormone to prevent the alterations produced by 6-methyl-prednisolone (Medrol) on the growing bone in rats. Endocrinology, 72: 470 (1963).

21. Mosier, H. D.: Failure of compensatory (catch-up) growth in the rat. Pediat. Res., 5: 59 (1971).

22. Peck, W. A., Brandt, J. and Miller, I.: Hydrocortisone-induced inhibition of protein synthesis and uridine incorporation in isolated bone cells in vitro. Proc. Natl. Acad. Sci. U. S. A., 57: 1599 (1967)

23. Sawano, S., Arimura, A., and Schally, A. V., et al.: Neonatal corticoid administration: Effects upon adult pituitary growth hormone and hypothalamic growth hormone-releasing hormone activity. Acta Endocrinol. (KBH), 61: 57 (1969).

24. Schapiro, S.: Some physiological, biochemical, and behavioral consequences of neonatal hormone administration: Cortisol and thyroxine. Gen. Comp. Endocrinol., 10: 214 (1968).

25. Shrader, R. E., and Zeman, F. J.: Skeletal development in rats as affected by maternal protein deprivation and postnatal food supply. J. Nutr., J03: 792 (1973).

26. Sobel, E. H., Raymond, C. S., Quinn, K. V., and Talbot, N. B.: The use of methyl testosterone to stimulate growth: Relative influence on skeletal maturation and linear growth. J. Clin. Endocrinol., 16: 241 (1956).

27. Stewart, R. J. C., and Sheppard, H. G.: Protein-calorie deficiency in rats: Growth and reproduction. Brit. J. Nutr., 25: 175 (1971).

28. Winick, M., and Coscia, A.: Cortisone-induced growth failure in neonatal rats. Pediat. Res., 2: 451 (1968).

29. This work was presented in part at the 1975 meetings of the American Pediatric Society, Society for Pediatric Research and at 1976 meetings of the European Society for Paediatric Endocrinology and European Society for Paediatric Research.

30. This research was supported in part by USPHS Project HD 05668 from the NIH. Bethesda, MD, and by Research Grant R-256-73 from the United Cerebral Palsy Research and Educational Foundation.

31. Requests for reprints should be addressed to: Edna H. Sobel, M.D., Albert Einstein College of Medicine, Bronx, NY 10461 (USA).

32. Received for publication July 19, 1977.

33. Accepted for publication December 14, 1977. 